\title{
AMCoR
}

Asahikawa Medical University Repository http://amcor.asahikawa-med.ac.jp/

Sleep and Biological Rhythms (2006) 4(2):87-104.

Neurobiological basis of state-dependent control of motor behaviors

TAKAKUSAKI, Kaoru ; SAITOH, Kazuya ; NONAKA, Satoshi ; OKUMURA, Toshikatsu ; MIYOKAWA, Naoyuki ; KOYAMA, Yoshimasa 


\section{Neurobiological Basis of State-Dependent Control of Motor Behavior}

Kaoru Takakusaki*, Kazuya Saitoh*, Satoshi Nonakał, Toshikatsu Okumura†, Naoyuki Miyokawa\#, and Yoshimasa Koyama**

*Department of Physiology, Asahikawa Medical College, Midorigaoka-higashi 2-1, Asahikawa 078-8510, JAPAN

$\ddagger$ Department of Otorhynolaryngology, Asahikawa Medical College,

Midorigaoka-higashi 2-1, Asahikawa 078-8510, JAPAN

†Department of General Medicine, Asahikawa Medical College, Midorigaoka-higashi 2-1, Asahikawa 078-8510, JAPAN

\#Division of Surgical Pathology, Asahikawa Medical College Hospital, Midorigaoka-higashi 2-1, Asahikawa 078-8510, JAPAN

**Department of Science and Technology, Fukushima University, 1 Kanayagawa, Fukushima 960-1296, JAPAN

Correspondence to:

Kaoru Takakusaki MD, PhD

Associate Professor

Department of Physiology

Asahikawa Medical College

Midorigaoka-higashi 2-1

Asahikawa 078-8510

JAPAN

TEL: +81-166-68-2331

FAX: +81-166-68-2339

E-mail: kusaki@asahikawa-med.ac.jp 


\section{Abstract}

We note the importance of an appropriate combination of excitability for the higher (neocortex, basal ganglia, and limbic system) and lower (brainstem-spinal cord) motor systems could be necessary for normal behavior during wakefulness and REM sleep. Neurotransmitters such as acetylcholine, the monoamines, GABA, and the orexins, would regulate the background excitability of the higher and lower motor systems so that an interaction of these systems could be appropriately maintained. Pathophysiological mechanisms of sleep deficiency may be induced by not only an organic disturbance of brain structures (hardware) but also by dysfunction of the neurotransmitter systems (software). From these considerations, we provide a hypothetical model for “state-dependent interaction of the higher and lower motor systems” for understanding normal behavior and pathophysiological mechanisms of sleep-related disorders such as narcolepsy and the REM-sleep behavioral syndrome. 


\section{Introduction}

A serious problem of the sleep deficiency which is associated with various diseases of the central nervous system is abnormal movement during sleeping. For example, more than $70 \%$ of Parkinsonian patients have a complicated sleep deficiency, such as insomnia, periodic limb movements, restless leg syndrome, rapid eye movement (REM) sleep behavioral disorders (RBD) and sleep attacks during wakefulness (Ferini-Strambi, 2000; Larsen and Tandberg, 2001). Narcolepsy, which is characterized by cataplexy (a sudden onset of muscular atonia which is induced by emotional stimuli), is also considered to be a typical sleep disorder that is closely linked with an orexinergic system deficiency (Nishino, 2003; Saper et al., 2001; Siegel, 2004).

Because sleep-awake cycles are controlled by various neurotransmitters acting on many areas in the central nervous system there is difficulty in determining the particular neural networks responsible for the pathogenesis of each sleep disorder. However, advances in the basic and clinical neurosciences have gradually clarified both the hardware (neural circuits) and software (neurotransmitters) which control movements during both wakefulness and REM sleep. Therefore a better way to interpret the pathogenesis of sleep disorders is to understand the neuronal mechanisms of motor control during wakefulness and sleeping.

In this review we consider a general design for motor control during wakefulness and REM sleep. We then discuss the neural mechanisms and operations of neurotransmitters on brainstem structures by which motor programs are called into action - a crucial and less well understood aspect of motor behavior. In particular, we focus on the prominent role of forebrain structures, such as the cerebral cortex, limbic system, and the basal ganglia, in the control of movements during wakefulness and REM sleep. We also provide a hypothetical framework for motor control systems that generate 
appropriate volitional and emotional motor behavior during wakefulness, and that induce a generalized motor inhibition during REM sleep. Finally, and based on this framework, we provide hypothetical models for understanding the mechanisms of state-dependent motor control and pathophysiological mechanisms of sleep-related disorders.

\section{General design of the motor control}

\section{1-1. Forebrain Control of Locomotor Behavior}

In an alert and arousal condition during wakefulness motor behavior depends on will and emotion. For example, locomotor behavior is composed of volitional, emotional, and automatic processes (Armstrong, 1986; Takakusaki et al., 2004b, 2004c). External stimuli can elicit alerting responses, leading to an animal being alert and cognitive to the external circumstances (Fig.1B). Then the animal starts locomotion. The initiation or termination of locomotion, and the avoidance of obstacles, requires volition and cognition. On the other hand a rhythmic alternation of limb movements and adjustment of postural muscle tone during locomotion are controlled unconsciously. Figure 1A shows the basic flow of signals in the nervous system for generating locomotor behavior. The volitional processes are controlled by cortico-basal ganglia loops, in addition to cortico-cerebellar loops (Middleton and Strick, 2000). The volitional signals arising from the motor cortex arrive at the brainstem, the spinal cord, and the basal ganglia. On the other hand if the external stimuli are noxious or very strong, an animal may immediately run away to avoid the stimuli, and not have cognition of the circumstances (Fig.1B). This emotional locomotor behavior can be brought about by a pathway through the limbic system (including hypothalamus) to the brainstem (Sinnamon, 1993).

Whether volitional or emotional, locomotor behavior is accompanied by automatic movement processes which are induced by a sequence of activation of basic 
motor programs in the brainstem and spinal cord (Grillner et al., 2005; Takakusaki et al., 2004c). The basic motor programs, involving neuronal networks designed to handle the basic motor repertoires required for survival (such as locomotion, posture, eye movements, and expression of emotions) are kept under tonic GABAergic inhibition from the basal ganglia. Therefore the basal ganglia could be responsible for selecting which motor program should be called into action (Grillner et al., 2005). The basic neuronal structures involved in the control of locomotion and postural muscle tone are located in the mesopontine tegmentum (Takakusaki et al., 2003a, 2004a 2004b, 2004c). One structure is the midbrain (or mesencephalic) locomotor region (MLR), and the other is the muscle tone inhibitory region in the pedunculopontine nucleus (PPN). In rats (Beckstead et al., 1979; Spann and Grofova, 1991; Saitoh et al., 2003) and cats (Moriizumi et al., 1988) the mesopontine tegmentum receives GABAergic efferents of the basal ganglia, with most from the substantia nigra pars reticulata ( $\mathrm{SNr}$ ).

Accordingly, the mesopontine tegmentum receives excitatory (glutamatergic) afferents from the cerebral cortex (Armstrong, 1986; Matsumura et al., 2000) and the limbic system (Mogenson et al., 1993), and inhibitory (GABAergic) afferents from the basal ganglia. The basal ganglia also have neuronal loops with both motor cortical areas and the limbic structures (Delong et al., 1984; Middleton and Strick, 2000). Therefore, basal ganglia efferents to both the forebrain and the midbrain may have a role in selection of volitionally-initiated and emotionally-triggered behavior so that an animal can elicit a variety of locomotor behavior, depending on the behavioral context.

\section{1-2. Brainstem mechanisms for controlling locomotion and postural muscle tone}

In both decerebrate (Shik et a1., 1966; Grillner, 1981; Takakusaki et al., 2003a) and alert (Mori et al., 1989) cats, locomotor movements can be evoked by either electrical 
or chemical stimulation of the MLR (Fig. 2A). The MLR largely corresponds to the cuneiform nucleus (CNF) and a region of the PPN (Fig. 2C). The non-cholinergic neurons in these areas are possibly involved in the generation of locomotion (Grillner et. al., 1997; Inglis and Winn, 1995; Jordan, 1998). Intracellular recording from an extensor motoneuron in an immobilized preparation has revealed that stimulation of the MLR first depolarized the membrane potential and then generated rhythmic membrane oscillations which were accompanied by bursting firing (Fig. 2Ba). Therefore signals from the MLR activate two systems. One is the "muscle tone excitatory system" arising from the locus coeruleus (LC) and raphe nuclei (RN), and the other is the "locomotor rhythm generating system" which is composed of the medullary reticulospinal tract and central pattern generators in the spinal cord (Fig. 3; Grillner, 1981; Rossignol, 1996).

On the other hand, either electrical or chemical stimulation applied to the ventrolateral part of the PPN can suppress postural muscle tone in decerebrate cats (Lai and Siegel, 1990; Takakusaki et al., 2003a, 2004a, 2004d). This PPN-induced muscular atonia is often accompanied by rapid eye movements (REM) (Fig. 2Ab). During PPN stimulation the hindlimb motoneurons innervating extensor and flexor muscles were hyperpolarized (Fig. 2Bb) by postsynaptic inhibition which was mediated by an inward chloride current (Takakusaki et al., 2004a). Choline acetyltransferase (ChAT) immunohistochemistry has revealed that cholinergic neurons are preferentially distributed in the inhibitory region rather than the locomotor region (Fig. 2C and D). This indicates that the muscle tone suppression could be due to an activation of cholinergic neurons. Moreover, it was observed that the PPN-induced muscular atonia was blocked by an injection of atropine sulfate into the medial pontine reticular formation (PRF) corresponding to the nucleus reticularis pontis oralis (NRPo). This result indicated that the muscular atonia was induced by an activation of cholinergic PPN neurons projecting 
to the NRPo (Takakusaki et al., 2003a; Fig.3). A series of our studies have demonstrated a “muscle tone inhibitory system” arising from the cholinoceptive NRPo neurons. These neurons activate reticulospinal neurons in the medullary nucleus reticularis gigantocellularis (NRGc) and inhibit extensor and flexor motoneurons via spinal inhibitory interneurons (Takakusaki et al., 1993, 1994). The muscle tone inhibitory system can provide postsynaptic inhibitory effects upon $\alpha$ - and $\gamma$-motoneurons, in parallel to interneurons intercalated in reflex pathways to motoneurons (Takakusaki et al., 2001, 2003b). This system may therefore also suppress locomotor movements by inhibiting the excitability of both motoneurons and spinal interneuronal networks responsible for generating locomotor rhythms (central pattern generators, CPG).

The GABAergic neurons arising from the SNr and projecting to the MLR and the PPN can modulate postural muscle tone and locomotion, as shown in Fig. 3. An activation of GABAergic efferents which project to the MLR from the lateral part of the SNr was observed to delay the onset of the MLR-induced locomotion and reduced step cycles of the locomotion. Moreover, an activation of GABAergic neurons in the middle and medial parts of the SNr inhibited the PPN-induced muscular atonia (Takakusaki et al., 2003a). These findings suggest that the nigro-tegmental projections (SNr-MLR/PPN) may modulate locomotion and postural muscle tone. The projections would also be responsible for the automatic regulation of postural muscle tone and the rhythmic alternation of limb movements which are associated with volitional and emotional locomotor behavior. The basal ganglia motor disorders may therefore include a dysfunction of the nigro-tegmental systems. This dysfunction could consequently lead to the production of abnormal muscle tone and gait failure.

\section{State-Dependent Motor Control}


Despite the electroencephalographic similarities, the psychological states of wakefulness and REM sleep are obviously different. The neocortex is active during wakefulness. However, the limbic areas are more active than the neocortex during REM sleep (Braun et al., 1997; Maquet, 2000, Steriade, 2001). This difference in the activity of the forebrain structures would be critical for state-dependent motor control. The highly organized sequence of the states of human sleep is actively generated by nuclei in the brainstem, of which the most important are the cholinergic nuclei of the mesopontine tegmentum (Datta, 2002, Datta and Hobson, 1994), the noradrenergic cells in the LC (Sakai and Crochet, 2004), and the serotonergic cells in the RN (Trulson et al., 1981). Through the ascending projections from these nuclei the activity of the group of relevant cells controls the degree of mental alertness, on a continuum from deep sleep to waking attentiveness. These cells also regulate the excitability of descending motor systems involved in the control of postural muscle tone and basic motor patterns, such as locomotion. The brainstem nuclei are, in turn, influenced by a circadian clock which is located in the suprachiasmatic nucleus and ventrolateral prepotic nucleus of the hypothalamus (see Pace-Schott and Hobson 2002).

Postural muscle tone is completely diminished during REM sleep despite a continued activity in the descending motor systems (Arduini et al., 1963; Bizzi et al., 1964). The pontomedullary reticular formation is a critical area for generating motor inhibition during REM sleep (Chase and Morales, 1990). However, the same area is involved in the control of posture and locomotion during wakefulness (Drew and Rossignol, 1990; Drew et al., 1986). Electrophysiological studies using decerebrate (Magoun and Rhines, 1946; Spraque and Chambers, 1954) and alert animals (Drew and Rossignol, 1990) have revealed that muscle tone inhibitory regions, and facilitatory regions, are intermingled within the pontomedullary reticular formation. Most 
importantly, the output from the reticular formation to the brainstem and spinal cord motoneurons is "state-dependent”. Chase and Wills (1979) demonstrated that stimulation of the pontomedullary reticular formation during wakefulness facilitated motor activity, whereas the same stimuli during REM sleep deeply suppressed motor activity (state-dependent response reversal). They suggested that the reticular core has “multifaceted functions” in terms of motor control during wakefulness and REM sleep (Chase et al., 1976). A question then arises, “How is response reversal realized?” Recent studies have shown that various neurotransmitters are involved in the response reversal phenomenon.

\section{Neurotransmitter systems and behavioral state}

\section{4-1. Acetylcholine and monoamine}

The original reciprocal-interaction model (Hobson et al., 1975; McCarely and Hobson, 1975) proposed that aminergic and cholinergic neurons of the mesopontine tegmentum interact in a manner that results in the ultradian alternation of REM and NREM sleep (Fig.4A). Based on recent advances (Pace-Schott and Hobson, 2002), it is generally agreed that REM sleep is facilitated by cholinergic REM-on cells and inhibited by aminergic REM-off cells. It has been reported that cholinergic REM-on cells in the PPN and the laterodorsal tegmental nucleus (LDT) postsynaptically excite non-cholinergic (possibly glutamatergic) PRF and MRF neurons and visa versa. Aminergic REM-off cells, such as noradrenergic LC neurons and serotonergic RN neurons, have inhibitory actions on REM-on cells. During waking, the aminergic systems are tonically activated and inhibit the pontine cholinergic and cholinoceptive systems. During NREM sleep, aminergic inhibition decreases and cholinergic excitation increases. At the onset of REM sleep aminergic inhibition is stopped, and cholinergic excitability is 
at a maximum (Fig.4B). The inhibition of noradrenergic LC neurons and the serotonergic dorsal raphe nucleus neurons by GABA contributes to the release of mesopontine REM-on cells from aminergic suppression (Maloney et al., 1999; Nitz and Siegel, 1997a, 1997b).

Neuroanatomical studies have revealed that the cholinoceptive cells in the PRF receive cholinergic inputs from the LDT and the PPN (Semba, 1993; Lai et al., 1993), and serotonergic inputs from the dorsal raphe nucleus (Semba 1993) and dorsal tegmental area (Kobayashi et al., 1994) (Fig.3). How then, is postural muscle tone controlled by cholinergic-monoaminergic interaction acting on the PRF? It has been reported that microinjections of carbachol, a cholinergic stimulant, into the PRF (which corresponds to the NRPo) induced a REM sleep-like state in chronic animals (Baghdoyan et al., 1984). Even in decerebrate cats, a microinjection of carbachol into the PRF induced a muscular atonia which resembled that observed during REM sleep (Morales et al., 1987; Takakusaki et al., 1993, 1994).

Carbachol-induced muscular atonia was observed to be associated with an increase in the firing frequency of a group of medullary reticulospinal neurons. A subsequent injection of serotonin into the same PRF area reduced the firing frequency of the MRF neurons and restored muscle tone (Fig.5A). A carbachol injection stopped spontaneous firing and hyperpolarized the membrane potential of soleus motoneurons, but a serotonin injection depolarized the neurons and was associated with muscle tone restoration (Fig.5B). Spike-triggered averaging revealed that the reticulospinal neurons produced inhibitory postsynaptic potentials (IPSPs) in motoneurons (Fig.5D). Several MRF neurons influenced both extensor and flexor motoneurons located in different lumbosacral segmental levels. Because the segmental latency of the IPSPs was 1.2-2.0 ms, a single interneuron may be located between the reticulospinal neuron and a 
motoneuron. These findings support the previous results that muscular atonia during REM sleep was due to a postsynaptic inhibition of brainstem and spinal motoneurons (Chase et al., 1980; Glenn and Dement, 1981; Morales and Chase, 1981) through the activation of the cholinoceptive pontomedullary reticulospinal tract, the so called muscle tone inhibitory system (Fig.3). Another group of medullary reticulospinal neurons, however, reduced their firing rate with carbachol and increased their firing rate with serotonin injections.

Moreover, stimulation of the pontomedullary reticular formation induced a sequence of excitatory postsynaptic potentials (EPSPs) and IPSPs in spinal motoneurons (Habaguchi et al., 2002; Takakusaki et al., 2001). An injection of carbachol into the NRPo augmented the IPSPs and reduced the EPSPs, but a serotonin injection reduced the IPSPs and augmented the EPSPs (Takakusaki et al., 1988). These studies have suggested that "response reversal” is possibly induced by cholinergic-serotonergic inputs to the PRF. Indeed, MLR-induced locomotion was inhibited, and postural muscle tone was suppressed by an injection of carbachol into the NRPo. However the locomotor movements were recommenced after an intrapontine injection of serotonin (Fig. 5E).

Other monoaminergic systems modulate the REM-NREM oscillator and might interact with aminergic and cholinergic control. Histamine is an amine transmitter of an arousal system that originates in neurons of the tuberomammillary nucleus of the posterior hypothalamus. The firing of this nucleus, like that of the serotonergic and noradrenergic neurons, is minimal during REM sleep (Saper et al., 2001). In contrast, the firing of midbrain dopaminergic neurons does not seem to vary in phase with the REM-NREM cycle (Miller et al., 1983; Trulson et al., 1981; Steinfels et al., 1983; Fig. 3B). However, dopamine may also be a controlling factor in motor control during wakefulness and REM sleep through the connection with the basal ganglia (nigrostriatal 
projection), limbic system (mesolimbic projection) and cerebral cortex (mesocoritcal projection). Such firing behaviors of dopamine neurons can be partly ascribed to the excitatory inputs from cholinergic and glutamatergic neurons in the PPN (Futami et al., 1995; Takakusaki et al., 1996). Although the mechanisms of dopaminergic influences have not fully understood, extrinsically augmented dopaminergic neurotransmission influences both sleep-wake and REM-NREM cycles. The enhancement of waking and prevention of sleep by dopamine re-uptake inhibitors and dopamine receptor agonists are the bases for their use in the treatment of narcolepsy and somnolence associated with Parkinson’s disease (Rye and Jankovic, 2002).

\section{4-2. Amino acid (GABA and the basal ganglia)}

The REM-NREM cycle is also influenced by GABA and glutamate. Inhibition by GABA both facilitates and inhibits REM sleep. For example, GABA inputs to the noradrenergic LC neurons and serotonergic DRN neurons from the PAG, SNr, dorsal paragigantocellular nucleus, and local interneurons, could suppress REM-off noradrenergic and serotonergic cells, thereby disinhibiting pontine cholinergic REM-on networks (Maloney et al., 1999; Nitz and Siegel, 1997a, 1997b; Torterolo et al., 2001). However GABA also directly inhibits the mesopontine cholinergic neurons which are responsible for the generation of PGO waves (Ulloor et al., 2004) and muscular atonia (Takakusaki et al., 2004d). There is also evidence for a GABA-mediated 'switch' between waking and REM in the NRPo (Xi a et al., 2001). Another inhibitory amino acid, glycine, is responsible for the inhibition of motoneurons during REM sleep (Chase et al., 1989). Glutamate may interact with cholinergic and cholinoceptive neurons to generate the exponential increase in mesopontine reticular activity that is associated with the onset of REM sleep (Inglis and Semba, 1995). Glutamatergic neurotransmission has also a 
prominent role in the thalamocortical processes that underlie the characteristic oscillations of NREM sleep (Steriade, 2001).

One of the major outputs of the basal ganglia is through GABAergic neurons. GABAergic neurons in the SNr have a direct projection to the thalamic nuclei (Hendry et. al., 1979; Parent et al., 1983) in addition to the PPN. Consequently, the basal ganglia may affect REM sleep by a modulation of the ascending reticular activation system through dual systems (Fig.6A). One system is through a direct nigro-thalamic projection. The other is mediated via the PPN. We have examined how the latter projection (the GABAergic SNr-PPN projection) altered the activity of the REM generator and the muscle tone inhibitory system (Takakusaki et al., 2004d; Fig.6B). In a decerebrate cat preparation, stimulation of the SNr alone did not alter the level of muscle tone or eye movements (Fig.6Ca). However, a conditioning stimulation applied to the lateral part of the SNr (filled circles in Fig. 6D) completely abolished the PPN-induced REM with atonia (Fig. 6Cb, c). On the other hand, stimuli applied to the middle part of the $\mathrm{SNr}$ (open circles in Fig. 6D) did not block REM but attenuated the muscular atonia, i.e., REM without atonia was induced by stimulation of the SNr (Fig. 6Cd). Because the effect of SNr stimulation was blocked by an injection into the PPN of bicuculline, a GABA receptor antagonist, the effect of the SNr stimulation was mediated by GABAergic neurons. These findings indicate that PPN neurons that are responsible for the induction of REM and atonia are under the inhibitory control of the basal ganglia. However, the above proposal does not agree with the following findings. First, it has been reported that a group of nigrotegmental neurons increased their firing rate during REM sleep (Datta et al., 1991). Second, it has been observed that a c-fos expression of GABAergic SNr neurons during REM sleep was higher than during non-REM sleep and wakefulness (Maloney et al., 2002). Accordingly, GABAergic SNr neurons do not necessarily 
contribute to the induction of REM sleep in a normal condition. Normally, cholinergic-monoaminergic reciprocity (see above) in the brainstem may play a more crucial role for the generation of REM sleep than the GABAergic SNr-PPN projection. However, an excessive GABAergic inhibition might affect REM sleep, as observed in the case of Parkinson's disease.

\section{4-3. Orexin (Hypocretin)}

Orexin (hypocretin) is a novel peptide which was recently discovered by Sakurai et al. (1998). Orexinergic neurons are located in the perifornical lateral hypothalamus and project to most areas of the central nervous system (Nambu et al., 1999; Peyron et al., 1998). A decreased number of orexin neurons has been reported in human narcolepsy patients (Thannickal et al., 2000). Canine narcolepsy is caused by exon skipping mutations of the orexin-receptor-2 gene (Hungs et al., 2001; Lin et al., 1999). Orexin knockout mice have also been used to examine the control of behavioral states by orexin (Chemelli, et al., 1999; Mochizuki et al., 2004). The orexin neurons project to the brainstem aminergic and cholinergic nuclei and mediate sleep-wakefulness regulation (Chemelli et al., 1999; Saper et al., 2001; Taheri et al., 2002). The firing rates of orexin neurons are observed to be higher during wakefulness and lower during REM sleep (Koyama et al., 2003; Mileykovskiy et al., 2005; Fig. 4B). In particular, a direct orexinergic projection to the LC may be in a position to enhance arousal and modulate plasticity in higher brain centers (van den Pol et al., 2002). The orexinergic system also excites dopaminergic (Korotkova et al., 2003), serotonergic (Liu et al., 2002; Takahashi et al., 2005), cholinergic (Burlet et al., 2002; Wu et al., 2004), glutamatergic (Li et al, 2002), peptidergic (Horvath et al., 1999) and GABAergic neurons (Korotkova et al., 2002; Wu et al., 2002). Orexin neurons, in turn, receive either excitatory or inhibitory effects from 
these neurons ( $\mathrm{Li}$ and van den Pol, 2005; Yamanaka et al., 2003). The orexinergic system also contributes to regulation of somatomotor control, feeding and energy balance, and to the control of vigilance states (Nishino, 2003; Okumura et al., 2001; Sakurai, 2002; Siegel, 2004).

Because the midbrain is one of the major targets of the orexinergic projection, we have examined how the orexinergic hypothalamic-brainstem system contributes to the control of postural muscle tone and locomotion (Takakusaki et al., 2005). We injected orexin-A (60 $\mu \mathrm{M}-1.0 \mathrm{mM}, 0.20-0.25 \mu \mathrm{l})$ into the MLR, the PPN, and the SNr, of decerebrate cats. We observed that orexin injections into the MLR (blue circles in Fig. 7A) generated locomotion (Fig.7B). On the other hand orexin injections into either the PPN or the SNr (black and red circles in Fig.7A) suppressed PPN-induced muscular atonia (Fig.7C and D). The latter effects were reversed by a subsequent injection of bicuculline into the PPN. This indicated that orexin may activate local GABAergic neurons in the PPN and GABAergic projection neurons in the SNr so that excitability of the cholinergic PPN neurons could be inhibited (Fig.7E). These findings suggest that the excitability seems to be higher in the locomotor system than in the atonia system in the presence of orexin. On the other hand, the excitability of the atonia system may be higher than that of the locomotor system in the absence of orexin. Thus emotional signals to the midbrain may induce locomotor behavior when there is normal functioning of the orexinergic system, but elicit cataplexy in narcolepsy when the orexinergic system is disturbed. Therefore orexin may be a determinant for the selection of emotional motor behavior (Takakusaki et al., 2005).

\section{Hypothesis: State-dependent Interaction of Higher and Lower Motor Systems}

\section{5-1. Excitability preference of the forebrain structures and state-dependent operation}




\section{of the brainstem-spinal cord}

Based on the considerations described above, we have provided a framework for understanding state-dependent motor control with respect to interactive mechanisms of the higher (forebrain) and lower (brainstem-spinal cord) motor systems (Fig. 8A). Because of higher monoaminergic and orexinergic influences on midbrain neurons during wakefulness, the excitability of descending muscle tone excitatory systems is maintained at a higher level. On the other hand, monoamines and orexins may reduce the background excitability of the muscle tone inhibitory system despite higher activity of cholinergic systems. These transmitter systems appropriately regulate arousal level, consciousness, and attention, by their direct actions on forebrain structures and their indirect actions via the ascending reticular activation system. This leads to an appropriate cognition of external and internal stimuli. Consequently volitional signals from the cerebral cortex and emotional signals from the limbic system to the brainstem may generate context dependent motor behavior.

In contrast, the excitability of the limbic system is higher than the neocortex during dreaming, in the period of REM sleep (Fig. 8B). Because of the highest firing rates of the REM-on mesopontine cholinergic neurons and the lowest firing rates of the monoaminergic REM-off cells and orexinergic neurons, the background excitability of the muscle tone inhibitory system is increased. But that of the excitatory system and locomotor generating system is greatly reduced. Accordingly the higher limbic activity during REM sleep may further facilitate the activity of the muscle tone inhibitory system. This results in a generalized motor inhibition (muscular atonia). We emphasize that forebrain structures control movements during both wakefulness and REM sleep. We postulate that a deficiency of state-dependent interaction between the higher and lower motor systems may be responsible for the pathogenesis sleep-related disorders such as 
narcolepsy and RBD.

\section{5-2. Pathophysiology of Narcolepsy}

In narcoleptic patients and animals, emotional signals elicit a sudden loss of muscular tonus (cataplexy; Nishino, 2003). Thus emotional signals may have the capability of not only evoking locomotor behavior in wakefulness (Fig.1) but also eliciting muscular atonia in narcolepsy. How then do emotional stimuli elicit muscular atonia in narcolepsy? In a normal awaking state higher orexinergic and monoaminergic influences enhance the excitability of the locomotor system and the muscle tone excitatory system, but reduce the excitability of the REM sleep generating system (Fig. 8A). Emotional signals via the limbic and hypothalamic structures (Derryberry and Tucker, 1992; Smith and Devito, 1984) to the midbrain may thus increase muscle tone and induce emotional locomotor behavior (Garcia-Rill et al., 2004; Shaikh et al., 1984; Sinammon; 1993; Skinner et al., 2004).

However, in the narcoleptic state the excitability of both the locomotor system and the muscle tone excitatory system would be reduced because of a deficiency of the orexinergic system. The orexin deficiency would increase the background excitability of the REM sleep generating system (Fig. 8C). Cataplexy in the narcoleptic state could be induced by a decrease in the activity of the descending excitatory systems (Siegel, 2004) as well as by an enhancement of the muscle tone inhibitory system. Consequently, emotional signals could suddenly induce muscular atonia (cataplexy) in narcolepsy. A narcoleptic patient is alert even in the cataleptic state because the neocortex is normally active during cataplexy.

However, according to this model, a lack of orexin input may increase REM sleep because of enhancement of the background excitability of the REM sleep 
generating system. Nonetheless, an increase in REM sleep has not been observed in human narcolepsy (Aldrich, 1992) and animal models (Mitler and Dement, 1977; Mochizuki et al., 2004). Therefore further examination is necessary to understand the pathophysiological mechanisms of narcolepsy and how the orexinergic system acts on other brainstem and forebrain structures.

\section{5-2. Pathophysiology of RBD}

In typical cases, patients with RBD have a lesion in the dorsolateral mesopontine tegmentum (Culebras and Moore, 1989; Kimura et al., 2000). The amount of sleep and the cycles of the sleep stages from non-REM sleep to REM sleep are normal. The distinctive finding is the presence of a persistent muscular tone during REM sleep. Episodes of RBD begin with a burst of excessive limb and body movements, and progress to more complex movements which can become vigorous and violent. Prominent muscle twitching and body movements accompany the phasic events of REM sleep.

The pathophysiology of RBD has not yet been established. The pathology could be similar to that of the experimental lesions in cats that have produced REM sleep without atonia. Experimentally, lesions of the PRF (Hendricks et al., 1982) and the medial part of the MRF (Schenkel and Siegel, 1989) in cats have produced REM sleep without atonia which is called “dream enactment” (Morrison, 1983). One of the mechanisms of the "REM without atonia" is schematically shown in Fig. 8D. First, an insufficient activity in REM-on cells that triggers the muscle tone inhibitory system may cause a release of motor activity during REM sleep, during which dreams are enacted. Therefore the excitability of spinal reflex loops, which include motoneurons and interneurons in reflex pathways, may be disinhibited by the reduced activity of the muscle tone inhibitory system. Second, signals from the limbic system during dreaming may activate the muscle 
tone excitatory system and the locomotor rhythm generating system via the MLR. Consequently, hyperactivity of the limbic system may induce movements during the period of REM sleep when the motor inhibition is insufficient.

However, about half of RBD patients are not associated with neuropathological disorders (Iranzo, 2002). Some subtle dysfunction of the balance between the inhibitory and excitatory systems during REM sleep may occur at the spinal cord, brainstem, or even higher forebrain regions. Several types of sleep disturbances are associated with Parkinson disease: insomnia, RBD, periodic limb movements, restless leg syndrome and sleep attacks during wakefulness (Ferini-Strambi, 2000; Larsen and Tandberg, 2001). In Parkinson disease the GABAergic output from the basal ganglia is possibly excessive because of a deficiency of the nigrostriatal dopaminergic systems (Delong, 1990; Wichmann and Delong, 1996). Because an increase in GABAergic basal ganglia efferents from the SNr not only suppresses REM and atonia but also induces REM without atonia in animal models (Fig.6Cb and c), a decrease in basal ganglia dopaminergic activity could be involved in the reduction of REM sleep and in RBD (Albin et al., 2000; Inglis and Winn, 1995; Rye et al., 1999). In addition, treatment of the disease with dopaminergic agonists may increase the dopaminergic influence upon limbic structure systems. This may result in enhancement of the activity of limbic systems during REM sleep.

\section{Summary}

We hypothesize that normal motor behavior during wakefulness and REM sleep is produced by an activation of an appropriate combination of higher and lower motor systems. The interaction is possibly regulated by various neurotransmitters, such as monoamine, acetylcholine and the orexins. An activation of the motor areas of the cerebral cortex causes activation of descending brainstem excitatory motor systems 
which produce voluntary movements. An activation of the limbic system, due to excessive emotional stimuli, elicits emotional motor behavior. However, in narcolepsy the excitability of the inhibitory system is enhanced even during wakefulness because of an orexin deficiency. Emotional stimuli may thus facilitate the activity of the inhibitory system, resulting in cataplexy. In normal REM sleep excitability is higher in the limbic system than in the neocortex. The excitatory drive from the limbic system to the brainstem may activate the muscle tone inhibitory system, resulting in muscular atonia. However, if the sequence of signals in the inhibitory system is interrupted, the excitatory drive from the limbic system would not inhibit movements but would activate the excitatory system during REM sleep. The result would be enactment of the contents of dreams.

The basal ganglia have connections with the cerebral cortex, limbic structures and the brainstem. The output of the basal ganglia may thus affect volitional and emotional behavior. A deficiency of these connections with the basal ganglia may be one cause of sleep disturbances in basal ganglia disorders. Dopamine may be an important factor for controlling movements during wakefulness and REM sleep. The dopaminergic neurons are relatively stable throughout the wake-sleep cycles, in contrast to other monoaminergic neurons. Sleep disturbance in Parkinsonian patients may also be ascribed to both a dopamine deficiency and an excessive dopamine influence due to medication.

In conclusion, appropriate combinations of the higher and lower motor systems are necessary for the expression of state-dependent motor behavior. The combinations can be regulated by various neurotransmitters (such as monoamines, acetylcholine, amino acid and the orexins) acting on the mesopontine tegmentum. Inappropriate interaction of the higher and lower motor systems can be the basis of pathophysiological mechanisms of sleep deficiency. Therefore sleep disorders can be induced not only by an 
organic disturbance of brain structures (hardware) but also by dysfunction of neurotransmitter systems (software). 


\section{References}

Albin RL, Koeppe RA, Chervin RD, Consens FB, Wernette K, Frey KA, Aldrich MS. 2001. Decreased striatal dopaminergic innervation in REM sleep behavior disorder. Neurology 55:1410-1412.

Aldrich MS. 1992. Narcolepsy. Neurology 42: 34-43.

Arduini A, Berlucchi B, Strata P. 1963. Pyramidal activity during sleep and wakefulness. Arch Ital Biol 101:530-544.

Armstrong DM. 1986. Supraspinal contribution to the initiation and control of locomotion in the cat. Prog Neurobiol 26:273-361.

Baghdoyan HA, Rodrigo-Angulo M L, McCarley RW, Hobson JA. 1984. Site-specific enhancement and suppression of desynchronized sleep signs following cholinergic stimulation of three brainstem regions. Brain Res 306:39-52.

Beckstead RM, Domesick VB, Nauta WJH. 1979. Efferent connections of the substantia nigra and ventral tegmental area in the rat. Brain Res 175:191-217.

Bizzi E, Pompeiano O, Somogyi I. 1964. Spontaneous activity of single vestibular neurons of unrestrained cats during sleep and wakefulness. Arch Ital Biol 102:308-330.

Braun AR, Balkin T J, Wesensten NJ, Carson RE, Varga M, Baldwin P, Selbie S, Belenky G, Herscovitch P. 1997. Regional cerebral blood flow throughout the sleep-wake cycle An $\mathrm{H}_{2}{ }^{15} \mathrm{O}$ PET study. Brain 120:1173-1197.

Burlet S, Tyler CJ, Leonard CS. 2002. Direct and indirect excitation of laterodorsal tegmental neurons by hypocretin/orexin peptides: Implication for wakefulness and Narcolepsy. J Neurosci 22:2862-2872.

Chase MH, Chankler SH, Nakamura Y. 1980. Intracellular determination of membrane potential of trigeminal motoneurons during sleep and wakefulness. J Neurophysiol 44:349-358.

Chase MH, Morales FR. 1990. The atonia and myoclonia of active (REM) sleep. Ann Rev Psychol 41:557-584.

Chase MH, Monoson R, Watanabe K, Kabb MI. 1976. Somatic reflex response-reversal 
of reticular origin. Exp Neurol 50:561-567.

Chase M H, Soja P J, Morales F R. 1989. Evidence that glycine mediates the post synaptic potentials that inhibit lumbar motorneurons during the atonia of active sleep. $\mathrm{J}$ Neurosci 9:743-751.

Chase MH, Wills N. 1979. Brain stem control of masseteric reflex activity during sleep and wakefulness: medulla. Exp Neurol 64:118-131.

Chemelli RM, Willie JT, Sinton CM, Elmquist JK, Scammell T, Lee C, Richardson JA, Williams SC, Xiong Y, Kisanuki Y, Fitch TE, Nakazato M, Hammer RE, Saper CB, Yanagisawa M. 1999. Narcolepsy in orexin knockout mice: molecular genetics of sleep regulation. Cell 98:437-451.

Culebras A, Moore JT. 1989. Magnetic resonance findings in REM sleep behavior disorder. Neurology 39:1519-1523.

Datta S. 2002. Evidence that REM sleep is controlled by the activation of brain stem pedunculopontine tegmental kainate receptor. J Neurophysiol. 87:1790-1978.

Datta S, Curró Dossi R, Paré D, Oakson G, Steriade M. 1991. Substantia nigra reticulata neurons during sleep-waking states: relation with ponto-geniculo-occipital waves. Brain Res 566:344-347.

Datta S, Hobson JA. 1994. Neuronal activity in the caudolateral peribrachial pons: relationship to PGO waves and rapid eye movements. J Neurophysiol 71:95-109.

Delong M.R. 1990. Primate models of movement disorders of basal ganglia origin. Trends Neurosci 13:281-289.

DeLong MR, Alexander GE, Georgopoulos AP, Crutcher MD, Mitchell SJ, Richardson RT. 1984. Role of basal ganglia in limb movements. Hum Neurobiol 2:235-244.

Derryberry D, Tucker DM. 1992. Neural mechanisms of emotion. J Consult Clin Psychol 60:329-338.

Drew T, Dubuc R, Rossignol S. 1986. Discharge patterns of reticulospinal and other reticular neurons in chronic unrestrained cats walking on a treadmill. J Neurophysiol 55:375-401.

Drew T, Rossignol S. 1990. Functional organization within the medullary reticular 
formation of the intact unanesthetized cat. II. Electromyographic activity evoked by microstimulation. J Neurophysiol 64:782-795.

Ferini-Strambi L, Zucconi M. 2000. REM sleep behavior disorder. Clin Neurophysiol Suppl 2:S136-40.

Futami T, Takakusaki K, Kitai ST., 1995. Glutamatergic and cholinergic inputs from the pedunculopontine tegmental nucleus to dopamine neurons in the substantia nigra pars compacta. Neuroscience Research. 21, 331-342.

Garcia-Rill E, Homma Y, Skinner RD. 2004. Arousal mechanisms related to posture and locomotion: 1. Descending modulation. Prog Brain Res 143:283-290.

Glenn LL, Dement WC. 1981. Membrane potential synaptic activity and excitability of hindlimb motoneurons during wakefulness and sleep. J Neurophysiol 4:6839-854.

Gottesmann C. 2002. The neurochemistry of waking and sleeping mental activity: The disinhibition-dopamine hypothesis. Psychiat Clin Neurosci 56:345-354.

Grillner S. 1981. Control of locomotion in bipeds tetrapods and fish. In: Brooks VB, editor. The Nervous System II. Bethesda: Am Physiol Soc Press. p 1179-1236.

Grillner S, Georgopoulos AP, Jordan LM. 1997. Selection and initiation of motor behavior. In: Stein PSG, Grillner S, Selverson AI, Stuart DG, editors. Neurons, Networks, and Motor Behavior. MIT Press. p 3-19.

Grillner S, Hellgren J, Menard A, Saitoh K, Wikstrom MA. 2005. Mechanisms for selection of basic motor programs--roles for the striatum and pallidum. Trends Neurosci 28:364-70.

Habaguchi T, Takakusaki K, Saitoh K, Sugimoto J, Sakamoto T. 2002. Medullary reticulospinal tract mediating the generalized motor inhibition in cats: II. Functional organization within the medullary reticular formation with respect to postsynaptic inhibition of forelimb and hindlimb motoneurons. Neuroscience 113:65-77.

Hendricks JC, Morrison AR, Mann GL. 1982. Different behaviors during paradoxical sleep without atonia depend on pontine lesion site. Brain Res 239:81-105.

Hendry SHC, Jones EG, Graham J. 1979. Thalamic relay nuclei for cerebellar and certain related fiber systems in the cat. J Comp Neurol 185:679-714. 
Hobson JA, McCarley RW, Wyzinki PW. 1975. Sleep cycle oscillation: reciprocal discharge by two brainstem neuronal groups. Science 189:55-58.

Horvath TL, Diano S, van den Pol AN. 1999. Synaptic interaction between hypocretin (orexin) and neuropeptide Y cells in the rodent and primate hypothalamus: a novel circuit implicated in metabolic and endocrine regulations. J Neurosci 19:1072-1087.

Hungs M, Fan J, Lin L, Lin X, Maki RA, Mignot E. 2001. Identification and functional analysis of mutations in the hypocretin (orexin) genes of narcoleptic canines. Genome Res 11; 531-539.

Inglis WL, Semba K. 1996. Colocalization of ionotropic glutamate receptor subunits with NADPH-diaphorase-containing neurons in the rat mesopontine tegmentum. J Comp Neurol 368:17-32.

Inglis WL, Winn P. 1995. The pedunculopontine tegmental nucleus: where the striatum meets the reticular formation. Prog Neurobiol 47:1-29.

Iranzo A, Santamaria J, Pujol J, Moreno A, Deus J, Tolosa E. 2002. Brainstem proton magnetic resonance spectroscopy in idopathic REM sleep behavior disorder. Sleep 25:867-870.

Jordan LM. 1998. Initiation of locomotion in mammals. Ann N Y Acad Sci 16:860;83-93.

Kimura K, Tachibana N, Kohyama J, Otsuka Y, Fukazawa S, Waki R. 2000. A discrete pontine ischemic lesion could cause REM sleep behavior disorder. Neurology 55:894-895.

Kobayashi Y, Matsuyama K, Mori S. 1994. Distribution of serotonin cells projecting to the pontomedullary reticular formation in the cat. Neurosci Res 20:43-55.

Korotkova TM, Eriksson KS, Haas HL, Brown RE. 2002. Selective excitation of GABAergic neurons in the substantia nigra of the rat by orexin/hypocretin in vitro. Regul Pept 104:83-89.

Korotkova TM, Sergeeva OA, Eriksson KS, Haas HL, Brown RE. 2003. Excitation of ventral tegmental area dopaminergic and nondopaminergic neurons by orexins/hypocretins. J Neurosci 23:7-11. 
Koyama Y, Takahashi K, Kodama T, Kayama Y. 2003. State-dependent activity of neurons in the perifornical hypothalamic area during sleep and waking. Neurosci 119:1209- 1219.

Lai YY, Clements JR, Siegel JM. 1993. Glutamatergic and cholinergic projections to the pontine inhibitory area identified with horseradish peroxidase retrograde transport and immunohistochemistry. J Comp Neurol 336:321-330.

Lai YY, Siegel JM. 1990. Muscle tone suppression and stepping produced by stimulation of midbrain and rostral pontine reticular formation. J Neurosci 10:2727-2734.

Larsen JP, Tandberg E. 2001. Sleep disorders in patients with Parkinson's disease: epidemiology and management. CNS Drugs 15:267-75.

Li Y, Gao XB, Sakurai T, van den Pol AN. 2002. Hypocretin/Orexin excites hypocretin neurons via a local glutamate neuron-A potential mechanism for orchestrating the hypothalamic arousal system. Neuron 36:1169-1181.

Li Y, van den Pol AN. 2005. Direct and indirect inhibition by catecholamines of hypocretin/orexin neurons. J Neurosci 25:173-183.

Lin L, Faraco J, Li R, Kadotani H, Rogers W, Lin X, Qiu X, de Jong, PJ, Nishino S, Mignot E (1999) The sleep disorder canine narcolepsy is caused by a mutation in the hypocretin (orexin) receptor 2 gene. Cell 98: 365-376.

Liu RJ, van den Pol AN, Aghajanian GK. 2002. Hypocretins (orexins) regulate serotonin neurons in the dorsal raphe nucleus by excitatory direct and inhibitory indirect actions. J Neurosci 22:9453-9464.

Magoun MW, Rhines R. 1946. An inhibitory mechanism in the bulbar reticular formation. J Neurophysiol 9:165-171.

Maloney KJ, Mainville L, Jones BE. Differential c-fos expression in cholinergic, aminergic and GABAergic cell groups of the pontomesencephalic tegmentum after paradoxical sleep deprivation and recovery. J Neurosci 19:3057-3072 (1999).

Maloney KJ, Mainville L, Jones BE. 2002. c-Fos expression in dopaminergic and GABAergic neurons of the ventral mesencephalic tegmentum after paradoxical sleep deprivation and recovery. Eur J Neurosci 15:1-6. 
Matsumura M, Nambu A, Yamaji Y, Watanabe K, Imai H, Inase M, Tokuno H, Takada M. 2000. Organization of somatic motor inputs from the frontal lobe to the pedunculopontine tegmental nucleus in the macaque monkey. Neuroscenc 98:97110.

Maquet P. 2000. Functional neuroimaging of normal human sleep by positron emission tomography. J Sleep Res 9:207-231

McCarley RW, Hobson JA. 1975. Neuronal excitability modulation over the sleep cycle: a structural and mathematical model. Science 189:58-60.

Middleton FA, Strick PL. 2000. Basal ganglia and cerebellar loops: motor and cognitive circuits. Brain Res Rev 31:236-250.

Mileykovskiy BY, Kiyashchenko LI, Siegel JM. 2005. Behavioral correlates of activity in identified hypocretin/orexin neurons. Neuron 46:787-798.

Miller JD, Farber J, Gatz P, Roffwarg H, German DC.. 1983. Activity of mesencephalic dopamine and non-dopamine neurons across stages of sleep and waking in the rat. Brain Res 273:133-141.

Mitler MM, Dement WC. 1977. Sleep studies on canine narcolepsy: pattern and cycle comparisons between affected and normal dogs. Electroencephalogr Clin Neurophysiol 43:691-699.

Mochizuki T, Crocker A, McCormack S, Yanagisawa M, Sakurai T, Scammell TE. 2004. Behavioral state instability in orexin knock-out mice. J Neurosci. 24:6291-6300

Mogensen GJ, Brudzynski SM, Wu M, Yang CR, Yim CCY. 1993. From motivation to action: A review of dopaminergic regulation of limbic-nucleus accumbens-ventral pallidum-pedunculopontine nucleus circuits involved in limbic-motor integration. In: Kalivas PW, editor. Limbic Motor Circuit and Neuropsychiatry. Boca Raton. FL: CRC. pp193-236.

Morales F, Chase MH. 1981. Postsynaptic control of lumbar motoneuron excitability during active sleep in the chronic cat. Brain Res 225:279-295.

Morales FR, Engelhardt J, Soja PJ, Pereda AE, Chase MH. 1987. Motoneuron properties during motor inhibition produced by microinjection of carbachol into the pontine 
reticular formation of the decerebrate cat. J Neurophysiol 57:1118-1128.

Mori S, Sakamoto T, Ohta Y, Takakusaki K, Matsuyama K. 1989. Site-specific postural and locomotor changes evoked in awake, freely moving intact cats by stimulating the brainstem. Brain Res 505:66-74.

Moriizumi T, Nakamura Y, Tokuno H, Kitao Y, Kudo M. 1988. Topographic projections from the basal ganglia to the nucleus tegmenti pedunculopontinus pars compacta of the cat with special reference to pallidal projections. Expl Brain Res 71:298-306.

Morrison AR. 1983. A window on the sleeping brain. Sci Am 248:94-102.

Nambu T, Sakurai T, Mizukami K, Hosoya Y, Yanagisawa M, Goto K. 1999.

Distribution of orexin neurons in the adult rat brain. Brain Res 827:243-260.

Nishino S. 2003. The hypocretin/orexin system in health and disease. Biol Psychiatry 54:87-95.

Nitz D, Siegel JM. 1997a. GABA release in the locus coeruleus as a function of sleep/wake state. Neuroscience 78:795-801.

Nitz D, Siegel JM. 1997b. GABA release in the dorsal raphe nucleus: role in the control of REM sleep. Am J Physiol 273:451-455.

Okumura T, Takeuchi S, Motomura W, Yamada H, Egashira S, Asahi S, Kanatani A, Ihara M, Kohgo Y. 2001. Requirement of intact disulfide bonds in orexin-A-induced stimulation of gastric acid secretion that is mediated by OX1 receptor activation. Biochem Biophys Res Commun 280:976-981.

Pace-Schott EF, Hobson JA. 2002. The neurobiology of sleep: genetics, cellular physiology and subcortical networks. Nature reviews 3:591-605.

Parent A, Mackey A, Smith Y, Boucher R. 1983. The output organization of the substantia nigra in primate as revealed by a retrograde double labeling method. Brain Res Bull 10:529-537.

Peyron C, Tighe DK, van den Pol AN, de Lecea L, Heller HC, Sutcliffe JG, Kilduff TS. 1998. Neurons containing hypocretin (orexin) project to multiple neuronal systems. J Neurosci 18:9996-10015.

Rossignol S. 1996. Neural control of stereotypic limb movements. In: Rowell LB, 
Shepherd JT, editors. Handbook of Physiology, sec. 12. New York: Oxford University Press. p 173-216.

Rye D B, Jankovic J. 2002. Emerging views of dopamine in modulating sleep/wake state from an unlikely source: PD. Neurology 58:341-346.

Rye DB, Johnston LH, Watts RL, Bliwise DL. 1999. Juvenile Parkinson's disease with REM sleep behavior disorder, sleepiness, and daytime REM onset. Neurology 53:1868-70.

Saitoh K, Hattori S, Song WJ, Isa T, Takakusaki K. 2003. Nigral GABAergic inhibition upon cholinergic neurons in the rat pedunculopontine tegmental nucleus. European Journal of Neuroscience 18:879-886.

Sakai K, Crochet S. 2004. Role of the locus coeruleus in the control of paradoxical sleep generation in the cat. Arch Ital Biol 142:421-427.

Sakurai T. 2002. Roles of orexins in regulation of feeding and wakefulness. Neuroreport 13:987-995.

Sakurai T, Amemiya A, Ishii M, Matsuzaki I, Chemelli RM, Tanaka H, Williams SC, Richardson JA, Kozlowski GP, Wilson S, Arch JR, Buckingham RE, Haynes AC, Carr SA, Annan RS, McNulty DE, Liu WS, Terrett JA, Elshourbagy NA, Bergsma DJ, Yanagisawa M. 1998. Orexins and orexin receptors: a family of hypothalamic neuropeptides and $\mathrm{G}$ protein-coupled receptors that regulate feeding behavior. Cell 92:573-85.

Saper CB, Chou TC, Scammell TE. 2001. The sleep switch: hypothalamic control of sleep and wakefulness. Trends Neurosci 24:726-731.

Schenkel E, Siegel JM.1989. REM sleep without atonia after lesions of the medial medulla. Neurosci Lett 98:159-165.

Semba K. 1993. Aminergic and cholinergic afferents to REM sleep induction regions of the pontine reticular formation in the rat. J Comp Neurol 330:543-556.

Siegel JM. 2004. Hypocretin (orexn): Role in normal behavior and neuropathology. Ann Rev Psychol 55:125-148.

Shaikh MB, Brutus M, Siegel BH, Siegel A. 1984. Differential control of aggression by 
the midbrain. Expl Neurol 83:436-442.

Shik ML, Severin FV, Orlovskii GN. 1966. Control of walking and running by means of electrical stimulation of the mid-brain. Biophysics 11:756-765.

Shimoda N, Tanaka H, Oka T, Takakusaki K, Mori S. 1991. Effects of intrapontine application of carbachol and serotonin upon posture and locomotion in decerebrate cats. In: Shimamura M, Grillner S, Edgarton VR, editors. Neurobiological Basis of Human Locomotion. Tokyo: Japan Scientific Society Press. p 51-56.

Sinnamon HM. 1993. Preoptic and hypothalamic neurons and initiation of locomotion in the anesthetized rat. Prog Neurobiol 41:323-344.

Skinner RD, Homma Y, Garcia-Rill E. 2004. Arousal mechanisms related to posture and locomotion: 2. Ascending modulation. Prog Brain Res 143:291-298.

Smith OA, DeVito JL. 1984. Central neural integration for the control of autonomic responses associated with emotion. Ann Rev Neurosci 7:43-65.

Spann BM, Grofova I. 1991. Nigro-pedunculopontine projection in the rat: an anterograde tracing study with Phaseolus Vulgaris-Leucoagglutinin (PHA-L). J Comp Neurol 311:375-388.

Sprague J M, Chambers WW. 1954. Control of posture by reticular formation and cerebellum in the intact, anesthetized and unanesthetized and in the decerebrated cat. Am J Physiol 176:52-64.

Steinfels GF, Heym J, Strecker RE, and Jacobs BL, 1983. Behavioral correlates of dopaminergic unit activity in freely moving cats. Brain Res 258: 217-228.

Steriade M. 2001. Active neocortical processes during quiescent sleep. Arch Ital Biol 139:37-51.

Taheri S, Zeitzer JM, Mignot E. 2002. The role of hypocretins (orexins) in sleep regulation and narcolepsy. Ann Rev Neurosci 25: 283-313.

Takahashi K, Wang Q-P, Guan J-L, Kayama Y, Shioda S, Koyama Y. 2005.

State-dependent effects of orexin on the serotonergic dorsal raphe neuronsin the rat. Reg Peptide 126:43-47.

Takakusaki K, Habaguchi T, Ohinata-Sugimoto J, Saitoh K, Sakamoto T. 2003a. Basal 
ganglia efferents to the brainstem centers controlling postural muscle tone and locomotion: a new concept for understanding motor disorders in basal ganglia dysfunction. Neuroscience 119:293-308.

Takakusaki K, Habaguchi T, Saitoh K, Kohyama J. 2004a. Changes in the excitability of hindlimb motoneuros during muscular atonia induced by stimulating the pedunculopontine tegmental nucleus in cats. Neuroscience 124:467-480.

Takakusaki K, Kohyama J, Matsuyama K. 2003b. Medullary reticulospinal tract mediating a generalized motor inhibition in cats: III. Functional organization of spinal interneurons in the lower lumbar segments. Neuroscience 121:731-746.

Takakusaki K, Kohyama J, Matsuyama K, Mori S. 2001. Medullary reticulospinal tract mediating the generalized motor inhibition in cats: parallel inhibitory mechanisms acting on motoneurons and on interneuronal transmission in reflex pathways. Neuroscience 103:511-527.

Takakusaki K, Kohyama J, Matsuyama K, Mori S. 1993. Synaptic mechanisms acting on lumbar motoneurons during postural augmentation induced by serotonin injection into the rostral pontine reticular formation in decerebrate cats.

Experimental Brain Research 93:471-482.

Takakusaki K, Ohinata-Sugimoto J, Saitoh K, Habaguchi T. 2004b. Role of basal ganglia-brainstem systems in the control of postural muscle tone and locomotion. Prog Brain Res 143:231-23

Takakusaki K, Saitoh K, Harada H, Kashiwayanagi M. 2004c. Role of basal ganglia brainstem pathways in the control of motor behaviors .Neuroscience Research 50:137-151.

Takakusaki K, Saitoh K, Harada H, Okumura T, Sakamoto T. 2004d. Evidence for a role of basal ganglia in the regulation of rapid eye movement sleep by electrical and chemical stimulation for the pedunculopontine tegmental nucleus and the substantia nigra pars reticulata in decerebrate cats. Neuroscience 124:207-220.

Takakusaki K, Sakamoto T, Mori S. 1988. Chemical modulation of medullary output neurons which control excitability of hindlimb alpha-motoneurons in cats. Soc Neurosci Abstr 14:180. 
Takakusaki K, Shimoda N, Matsuyama K, Mori S. 1994. Discharge properties of medullary reticulospinal neurons during postural changes induced by intrapontine injections of carbachol, atropine and serotonin, and their functional linkages to hindlimb motoneurons in cats. Experimental Brain Research 99:361-374.

Takakusaki K, Shiroyama T, Yamamoto T, Kitai ST., 1996. Cholinergic and noncholinergic tegmental pedunculopontine projection neurons in rats revealed by intracellular labeling. Journal of Comparative Neurology. 371, 345-361.

Takakusaki K, Takahashi K, Saitoh K, Harada H, Okumura T, Kayama Y, Koyama Y. 2005. Orexinergic projections to the midbrain mediate alternation of emotional behavioral states from locomotion to cataplexy. J Physiol 568: 1003-1020.

Thannickal TC, Moore RY, Nienhuis R, Ramanathan L, Gulyani S, Aldrich M, Cornford M, Siegel JM. 2000. Reduced number of hypocretin neurons in human narcolepsy. Neuron 27:469-474.

Torterolo P, Yamuy J, Sampogna S, Morales FR, Chase MH. 2001. GABAergic neurons of the laterodorsal and pedunculopontine tegmental nuclei of the cat express c-fos during carbachol-induced active sleep. Brain Res 892:309-319.

Trulson ME, Jacobs BL, Morrison AR. 1981. Raphe unit activity during REM sleep in normal cats and in pontine lesioned cats displaying REM sleep without atonia. Brain Res 226:75-91.

Trulson M E, Preussler D W, Howell A G. 1981 Activity of the substantia nigra across the sleep-wake cycle in freely moving cats. Neurosci Lett 26:183-188.

Ulloor J, Mavanji V, Saha S, Siwek DF, Datta S, Spontaneous REM sleep is modulated by the activation of the pedunculopontine tegmental $\mathrm{GABA}_{\mathrm{B}}$ receptors in the freely moving rat. J Neurophysiol 91: 1822-1831, 2004.

van den Pol AN, Ghosh PK, Liu RJ, Li Y, Aghajanian GK, Gao XB. 2002. Hypocretin (orexin) enhances neuron activity and cell synchrony in developing mouse GFP-expressing locus coeruleus. J Physiol 541:169-185.

Wichmann T, Delong MR. 1996. Functional and pathological models of the basal ganglia. Curr Opin Neurobiol 6:751-758. 
Wu M, Zaborszky L, Hajszan T, van den Pol AN, Alreja M. 2004. Hypocretin/orexin innervation and excitation of identified septohippocampal cholinergic neurons. J Neurosci 24:3527-3536.

Wu M, Zhang Z, Leranth C, Xu C, van den Pol AN, Alreja M. 2002. Hypocretin increases impulse flow in the septohippocampal GABAergic pathway: implications for arousal via a mechanism of hippocampal disinhibition. J Neurosci 22:7754-7765.

Xi M C, Morales F R, Chase M H. 2001. Induction of wakefulness and inhibition of active sleep by GABAergic processes in the nucleus pontis oralis. Arch Ital Biol 139:125-145.

Yamanaka A, Muraki Y, Tsujino N, Goto K, Sakurai T. 2003. Regulation of orexin neurons by the monoaminergic and cholinergic systems. Biochem Biophys Res Commun 303:120-129. 


\section{Figure legends}

Figure 1. Neural basis of locomotor behavior.

A. Signal flow involved in the volitional, emotional, and automatic processes of generating locomotor behavior (modified from Takakusaki et al., 2004b).

B. External signals elicited a sequence of locomotor behavior. Each figure is depicted from a video tape with intervals of $0.2-0.1$ seconds. Abbreviations: GPi, internal segment of globus pallidus (which corresponds to entopeduncular nucleus of lower mammals); SNr, substantia nigra pars reticulata. See text for detailed explanation.

Figure 2 Mesopontine tegmental regions involved in locomotion and postural muscle tone in the decerebrate cat.

A. Stimulus sites on a parasagittal plane of the brainstem. (a). Repetitive stimulation (50 $\mathrm{Hz}, 40 \mu \mathrm{A}$ lasting for 8 seconds) of the mesencephalic locomotor region (MLR) induced locomotion on the moving treadmill belt. (b). Repetitive stimulation (50 Hz, $40 \mu \mathrm{A}$ lasting for 10 seconds) of the pedunculopontine tegmental nucleus (PPN) induced muscular atonia associated with rapid eye movements (REM). The upper trace is an electro-oculogram (EOG) and the lower traces are electromyograms (EMG) obtained from the left (L) and right (R) soleus muscles. B. Changes in the excitability of a soleus motoneuron following MLR (a) and PPN (b) stimulation. Stimulation of the MLR (50 Hz, $40 \mu \mathrm{A}$ lasting for 15 seconds) first depolarized (indicated by a triangle), and then generated oscillations of membrane potentials of the motoneuron (a). Stimulation of the PPN (50 Hz, $40 \mu \mathrm{A}$ lasting for 12 seconds) stopped the firing and hyperpolarized the membrane. C. Optimal stimulus sites for evoking locomotion $(n=9)$ and muscular atonia $(\mathrm{n}=11)$ on parasagittal (a) and coronal (b) planes of the brainstem. D. Distribution of cholinergic neurons identified by choline-acetyltransferase (ChAT) 
immunohistochemistry. See text for further explanations. Abbreviations: CNF, cuneiform nucleus; IC, inferior colliculus; LDT, laterodorsal tegmental nucleus; NRPo, nucleus reticularis pontis oralis; SC, superior colliculus; SCP, superior cerebellar peduncle. A, C and D are modified from Takakusaki et al., (2005). B is modified from Takakusaki et al., (2004a).

Figure 3. Possible neuronal systems controlling locomotion and postural muscle tone. Signals from the MLR activate the muscle tone excitatory system arising from the locus coeruleus (LC) and raphe nuclei (RN), and the locomotor rhythm generating system composed of medullary reticulospinal neurons and central pattern generators (CPG). Signals from the muscle tone inhibitory region in the PPN activate the REM generator, and the muscle tone inhibitory system composed of pontine reticular formation (PRF) neurons, medullary reticular formation (MRF) neurons and spinal inhibitory interneurons. The interneurons inhibit motoneurons, and possibly CPG. GABAergic neurons in the SNr inhibit PPN cholinergic neurons. The midbrain area receives orexinergic input from the prefornical lateral hypothalamus. This schema has been modified from Takakusaki et al., 2004c. Abbreviations: NA, noradrenalin; 5-HT, serotonin.

Figure 4. State-dependent changes in neurotransmitters.

A. Reciprocal interaction of REM-on cells and REM-off cells in relation to vigilance states. Monoaminergic REM-off cells inhibit REM-on cells (modified from Pace-Schott and Hobson, 2002). B. Relative changes in acetylcholine (ACh), serotonin/noradrenalin (5-HT/NA), orexin and dopamine (DA). This schema is based on descriptions in following papers (Gottesmann, 2002; Koyama et al., 2003; Mileykovskiy et al., 2005; Miller JD, et al., 1983; Pace-Schott and Hobson, 2002; Steinfels et al., 1983). See text for 
explanation.

Figure 5. Cholinergic-serotonergic interaction in the pontine reticular formation controls postural muscle tone and locomotion.

A. Changes in the firing rate of medullary reticulospinal neurons (upper) associated with changes in muscle tone (lower traces) following injections of carbachol (4 $\mu \mathrm{g} / 0.25 \mu \mathrm{l})$ and serotonin $(4 \mu \mathrm{g} / 0.25 \mu \mathrm{l})$ into the nucleus reticularis pontis oralis (NRPo). The firing frequency of the reticulospinal neuron was increased, and reduced, by carbachol and serotonin injections, respectively. B. Changes in membrane potential of soleus motoneurons following injections of carbachol $(1.6 \mu \mathrm{g} / 0.10 \mu \mathrm{l})$ and serotonin $(12.0$ $\mu \mathrm{g} / 0.5 \mu \mathrm{l})$.into the NRPo. Carbachol injection resulted in muscular atonia which was associated with cessation of spontaneous firing and membrane hyperpolarization of the motoneuron. Serotonin injection restored muscle tone together with membrane depolarization and recovery of tonic firing of the motoneuron. C. Orthodromic (a) and antidromic (b) responses of the medullary reticulospinal neuron with a firing rate that was increased by an intrapontine carbachol injection. D. Spike-triggered averaging of membrane potentials of a posterior biceps semitendinosus (PBSt) motoneuron by the tonic firing of the reticulospinal neuron shown in C. (a) A reticulospinal neuron as a time reference. (b) Superimposition of 3 IPSPs which were averaged with 1024 sweeps. A downward arrow indicates the onset of the IPSP. (c) Extracellular control. The triangles show descending volleys of the reticulospinal neuron recorded in both intracellular and exracellular recordings. E. Changes in MLR-induced locomotion following carbachol and serotonin injections. Locomotion evoked by stimulating the MLR $(40 \mu \mathrm{A})$ on the moving treadmill belt (left) was suppressed within 5 minutes after a carbachol injection (4 $\mu \mathrm{g} / 0.25 \mu \mathrm{l}$ ) into the NRPo. A serotonin injection into the NRPo, which was 30 minutes 
after the carbachol injection, restored the MLR-induced locomotion. Figures A, C, and D, have been modified from Takakusaki et al., 1994. Figure B, has been modified from Takakusaki et al., 1993. Figure E has been modified from Shimoda et al., 1991.

Figure 6. Basal ganglia modulation of REM sleep.

A. A schematic illustration of basal ganglia regulation of REM sleep by modulating the thalamocortical neurons and the PPN neurons. B. Schematic presentation of the experimental design. C. Stimulation of the $\mathrm{SNr}(100 \mathrm{~Hz}$ and $40 \mu \mathrm{A})$ did not alter eye movements and muscle tone (a). Stimulation of the PPN (50 Hz and $40 \mu \mathrm{A}$ ) induced REM and atonia (b). Conditioning stimulation of the lateral part of the SNr abolished the PPN-induced REM and atonia (c). Conditioning stimulation of the mid SNr abolished muscular atonia but not REM (d). The upper trace and lower traces are EOG, and left and right soleus muscle EMG, respectively. D. Optimal stimulus sites for blocking the PPN-induced REM and atonia (filled circles) and for induction of REM without atonia (open circles). Figure A has been modified from Takakusaki et al., 2004d. Figures B-D have been modified from Takakusaki et al., 2004c.

Figure 7. Orexinergic modulation of locomotion, postural muscle tone, and REM.

A. Injection sites of orexin A. Injections denoted by the blue color facilitated locomotion. Injections denoted by the black and red colors suppressed PPN-induced muscular atonia. Injections denoted by the purple color (indicated by a star) facilitated locomotion and suppressed PPN-induced atonia. B. Locomotor movements induced by an orexin injection into the cuneiform nucleus (CNF). C. (a) PPN stimulation (50 Hz, $30 \mu \mathrm{A}$ ) induced REM and muscular atonia. (b) An injection of orexin-A (100 $\mu \mathrm{M}, 0.25 \mu \mathrm{l})$ into the PPN abolished the PPN effects. D. PPN-induced REM and muscular atonia (a) was 
blocked by an injection of orexin-A (100 $\mu \mathrm{M}, 0.25 \mu \mathrm{l})$ into the SNr (b). E. Possible mechanisms of orexin effects upon the mesopontine tegmentum. See text for detailed explanation.

Figure 8. Hypothetical models of state-dependent motor behavior. See text for detailed explanations. 

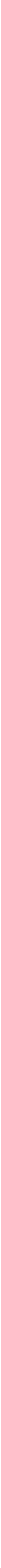


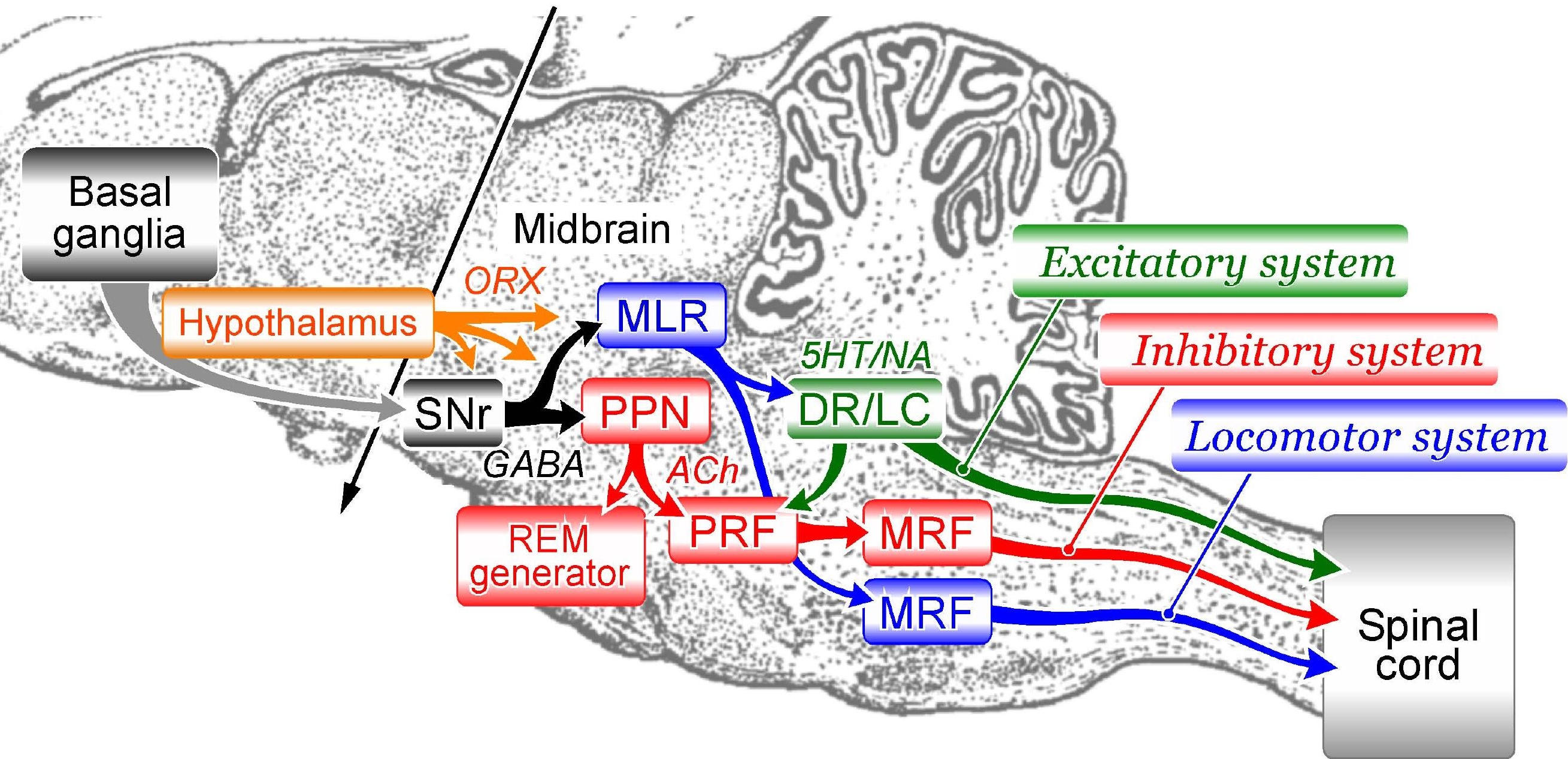


Awake

NREM

REM

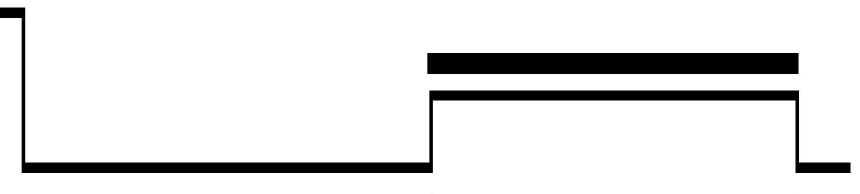

Dynamic model

REM-off cells

LC (NA), RN (5HT)

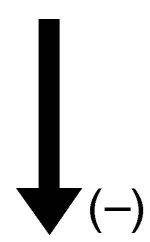

REM-on cells
Awake NREM REM

$\mathrm{ACh}$

NA $5 \mathrm{HT}$

Orexin
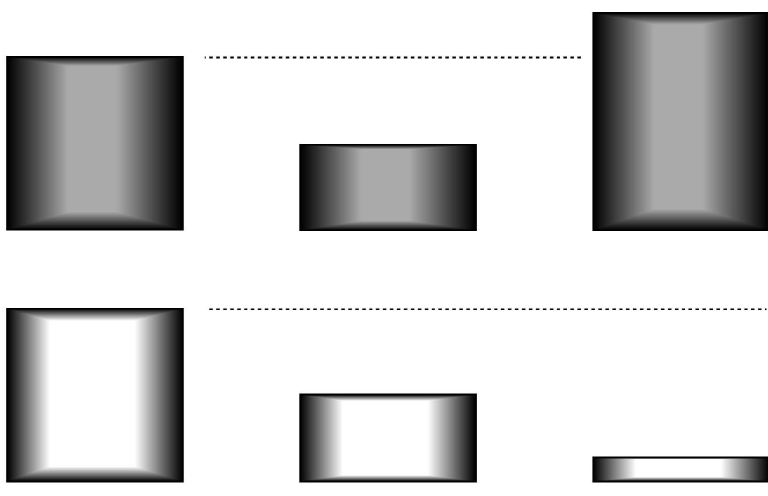
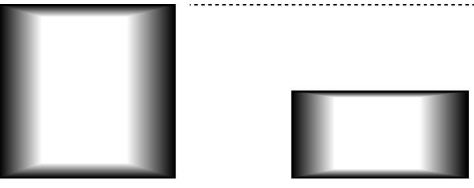

DA 
elpxә

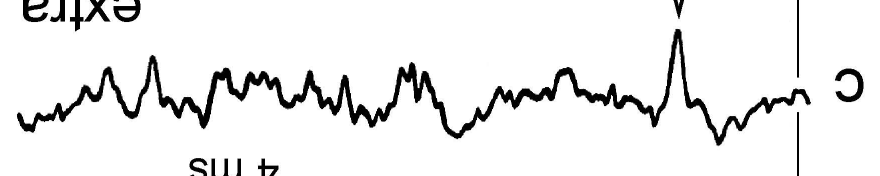

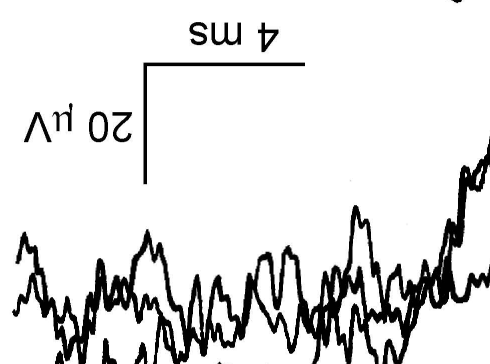

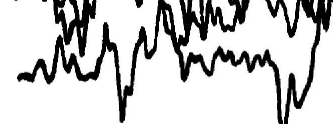
uounəuołour isgd $\varepsilon \times$ sdəəMs $\downarrow Z 0 \mathrm{~L}$

(OכyN) uoınəu sy

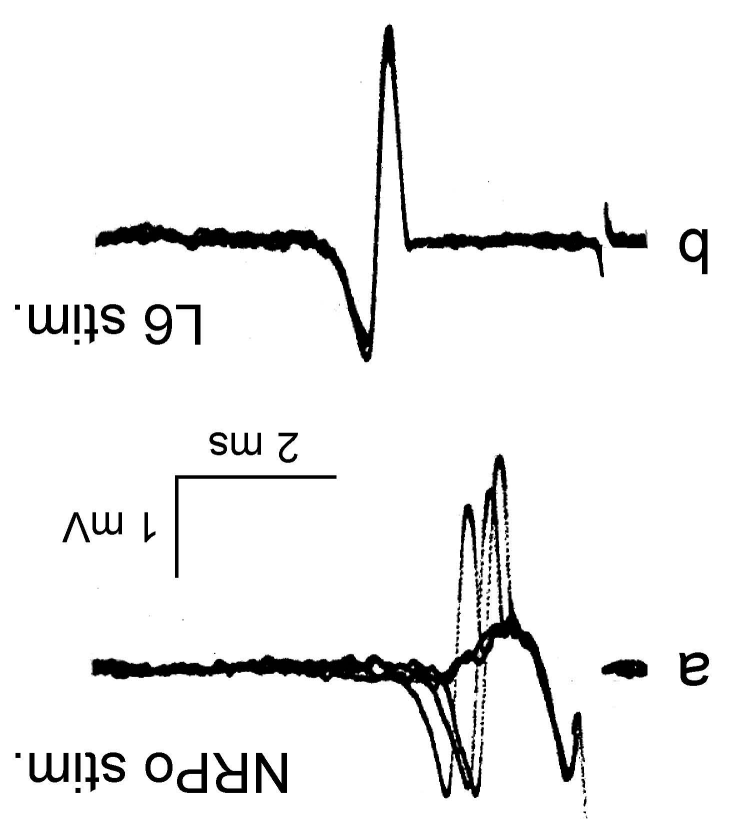

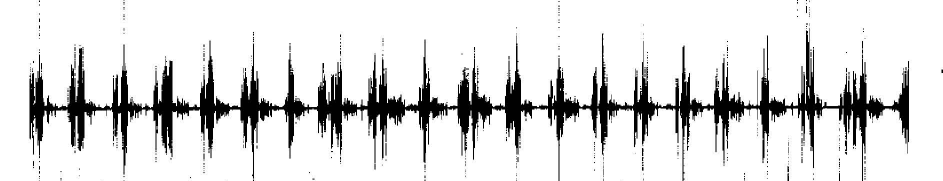

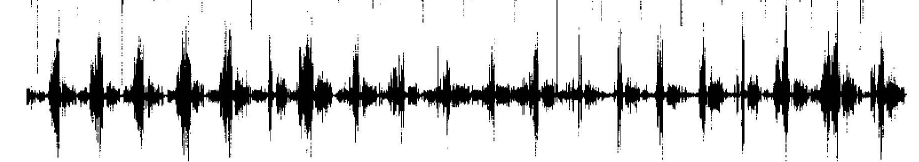
u!notoıs

(7) ЭW

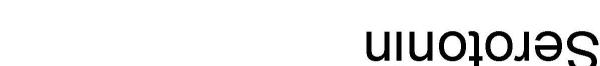

jочэequeว

$92 \quad 92$

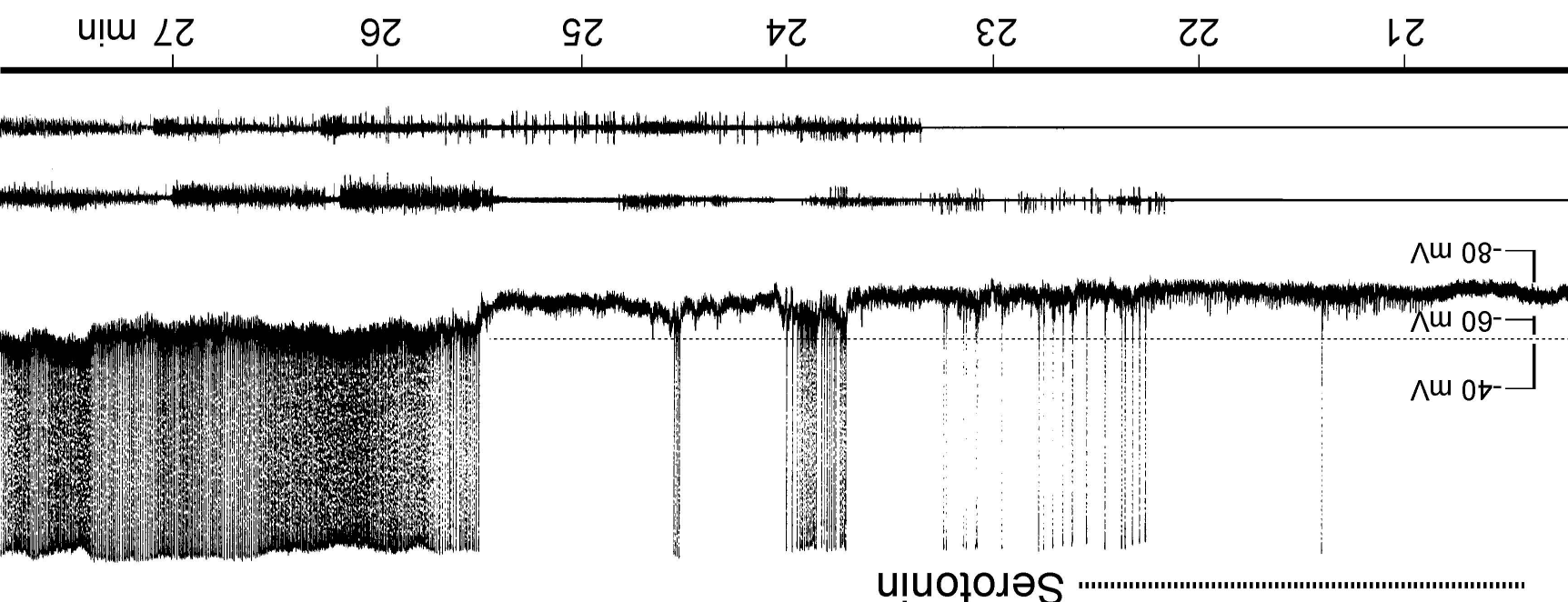

uluotodəS

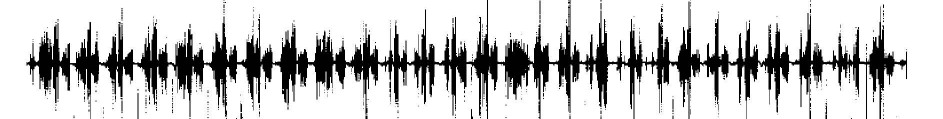

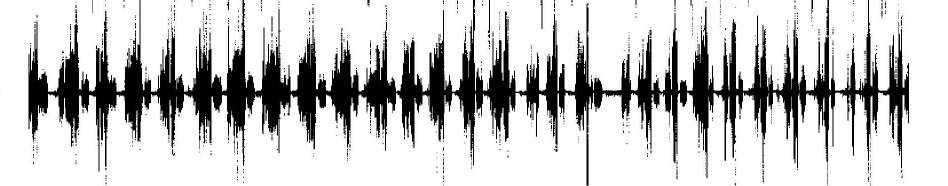

ןаяบ00
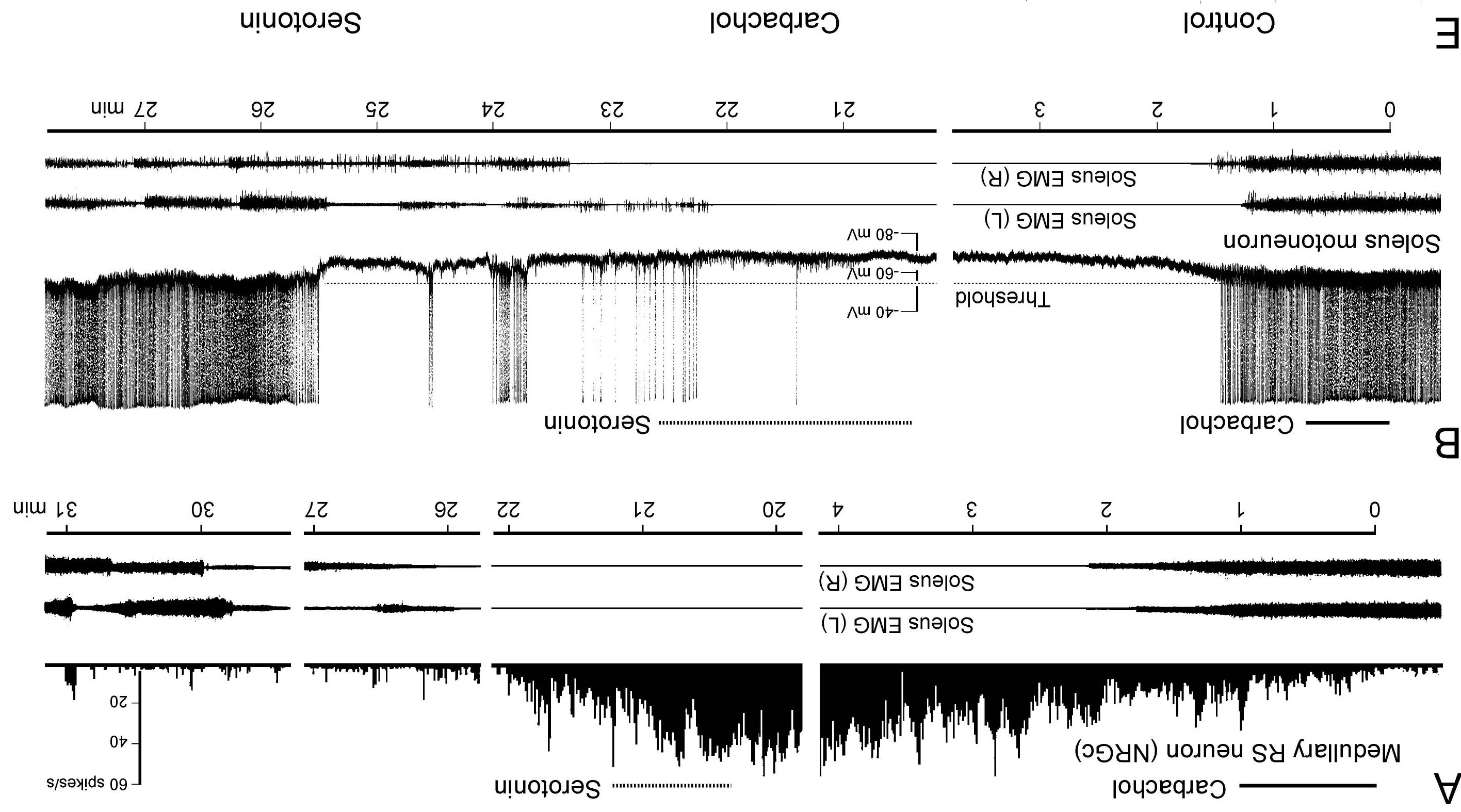

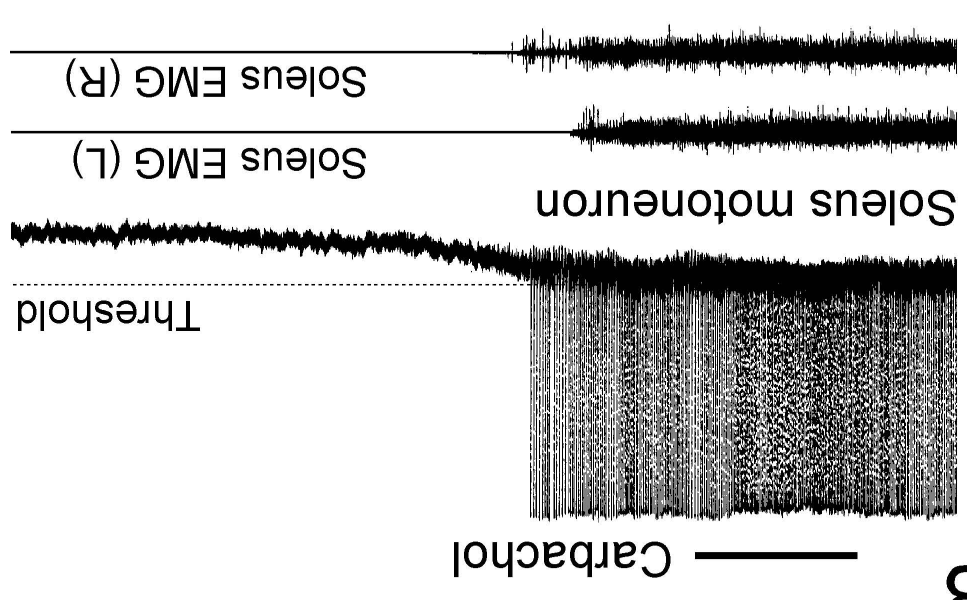

joujequeJ 
EEG desynchronization

\section{Cerebral cortex}

\section{Basal ganglia

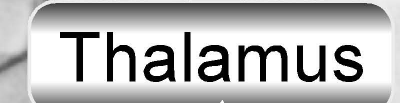

ARAS

\section{PPN}

\section{REM generator}

Rapid eye movements

Inhibitory system

Muscular atonia

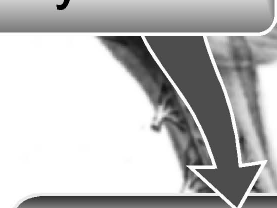

Spinal cord
B Stim. Stim.

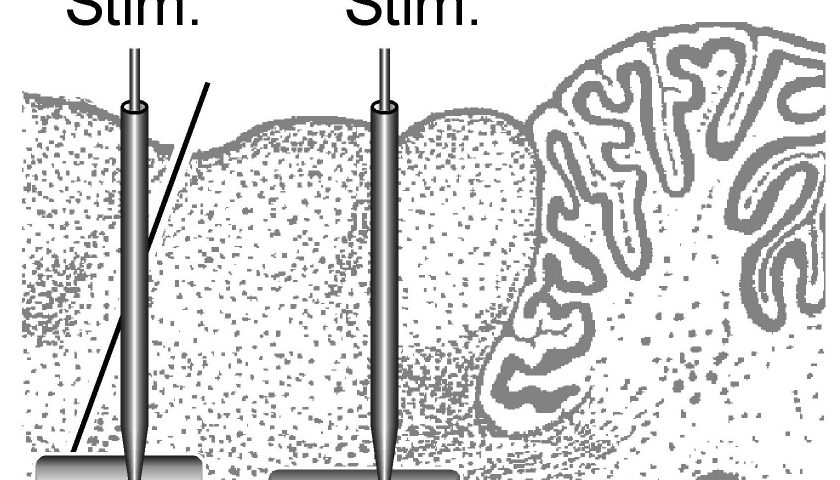

$\mathrm{SNr} \Rightarrow \mathrm{PPN}$

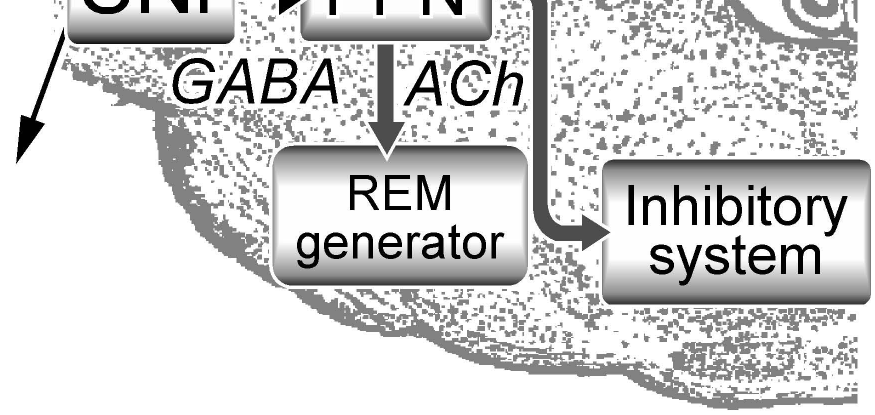

D

Inhibition of REM-atonia REM without atonia

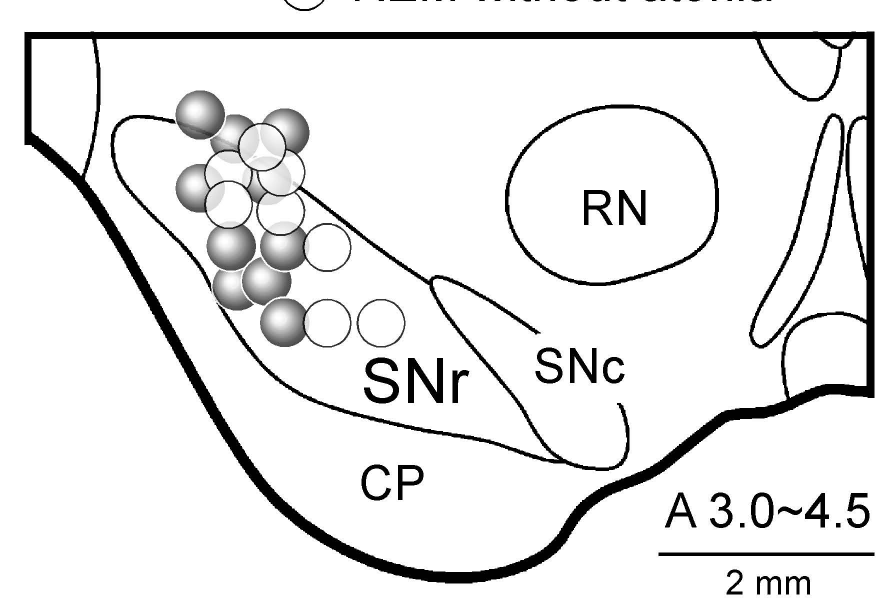

a

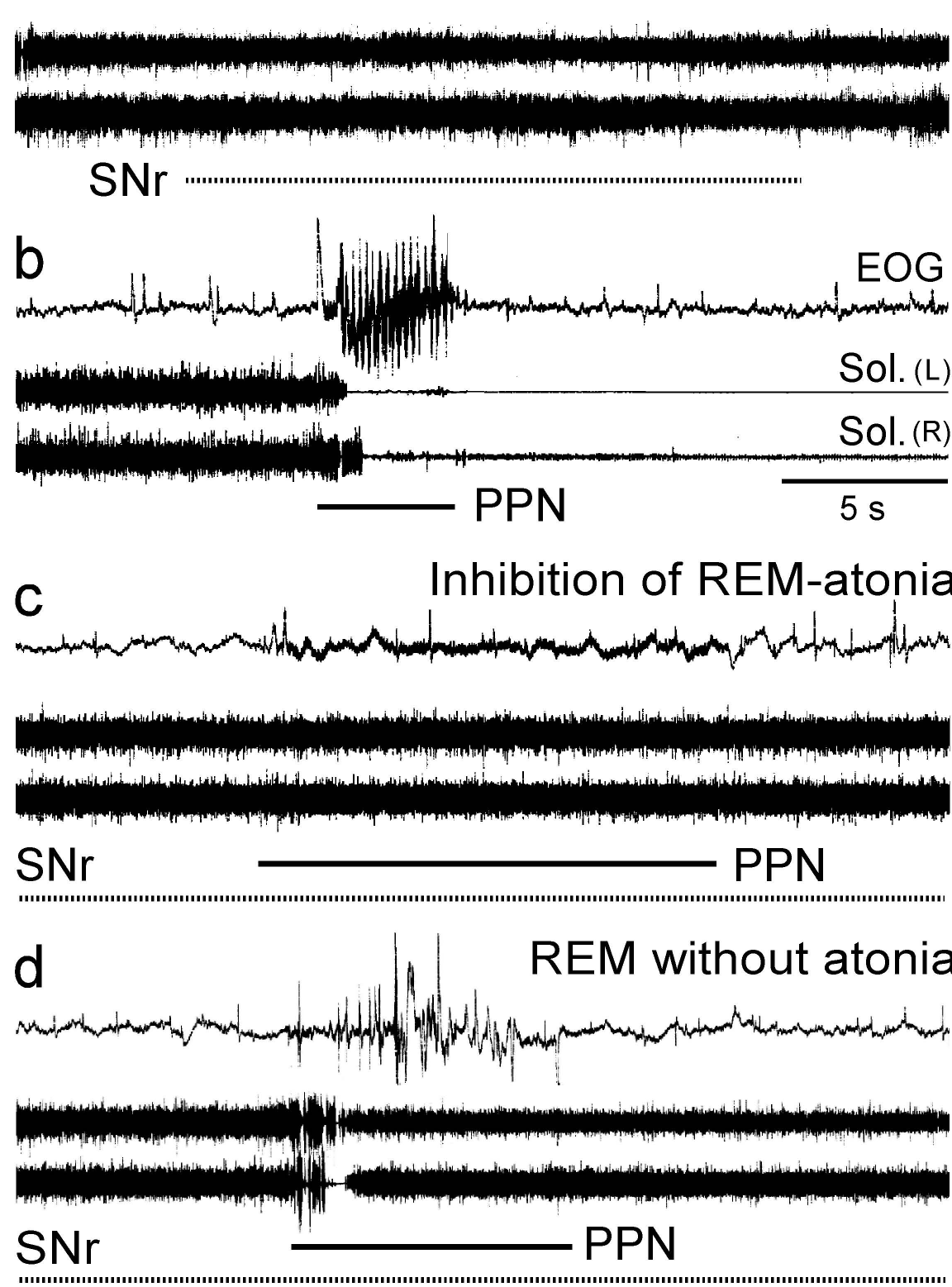



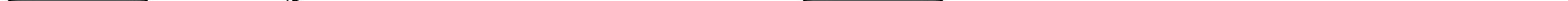